\title{
Estimation of on-site directional wave spectra using measured hull stresses on 14,000 TEU large container ships
}

\author{
Xi Chen $^{1}$ (D) $\cdot$ Tetsuo Okada $^{1} \cdot$ Yasumi Kawamura $^{1} \cdot$ Taiga Mitsuyuki $^{1}$
}

Received: 11 April 2019 / Accepted: 30 July 2019 / Published online: 30 August 2019

(c) The Author(s) 2019

\begin{abstract}
Container ships are becoming larger and larger in recent years, requiring more evident assurance of the structural safety. To achieve this, it is essential to grasp actual stress history experienced by the ship structures to facilitate efficient design and maintenance, and to use them for optimal operation of the ship. To perform accurate estimation of these stress histories, it is important to precisely estimate the sea state which the ship is actually encountering. In this study, the authors studied a new method to estimate directional wave spectra using measured ship responses and discussed the following three cases. The first one is the combination of two components, vertical bending stress and horizontal bending stress. The second one is the combination of three components, vertical bending stress, horizontal bending stress and double bottom bending stress. The last one is the combination of three components of ship motion (pitch, roll and heave). The estimated sea states are compared with the ocean wave hindcast database and radar data, and then, accuracy and selection of appropriate combination of the responses are discussed.
\end{abstract}

Keywords Container ship $\cdot$ Monitoring $\cdot$ Measurement $\cdot$ Wave spectrum $\cdot$ Vertical bending stress $\cdot$ Horizontal bending stress $\cdot$ Double bottom bending stress

\section{Introduction}

Container ships are becoming larger and larger in recent years, requiring more evident assurance of the structural safety. To achieve this, it is essential to grasp actual stress history experienced by the ship structures to facilitate efficient design and maintenance, and to use them for optimal operation of the ship. To perform accurate estimation of these stress histories, it is important to precisely estimate the sea state which the ship is actually encountering.

Okada [1] proposed a concept to evaluate the directional wave spectrum from the measurement results of the motion

Xi Chen

chin-xi-vr@ynu.ac.jp

Tetsuo Okada

okada-t@ynu.ac.jp

Yasumi Kawamura

kawamura-yasumi-zx@ynu.ac.jp

Taiga Mitsuyuki

mitsuyuki-taiga-my@ynu.ac.jp

1 Faculty of Engineering, Yokohama National University, Kanagawa 240-8501, Japan and stress of the hull, and to use it to estimate the stress history at any parts of the ship hull in combination with the associated stress response functions. This kind of concept is considered to be realized by giving shape to the digital twin as illustrated in Fig. 1. The digital data consist of the Basic Ship Model (upper middle in Fig. 1) as well as the Basic Ship Characteristics (lower middle in Fig. 1) which include response functions throughout all the parts of the hull structures. On the other hand, onboard the actual ship, real-time monitoring is conducted with regard to various information including ship motion and stresses at specific locations (upper left in Fig. 1). The measured time series data are processed into response spectra and used for numerical simulation. In this process, accurate wave information (upper right in Fig. 1) is essential to calculate the stress history at various parts of the ship, to be further utilized in the structural integrity assessment (bottom in Fig. 1).

There are many methodologies to identify actually encountering sea state, such as visual observation, wave radar system, wave hindcast, and so on. Pros and cons of various methodologies are summarized, e.g., in Ref. [2], but usage of measured ship responses for the wave estimation is considered to be promising, taking account of its good 


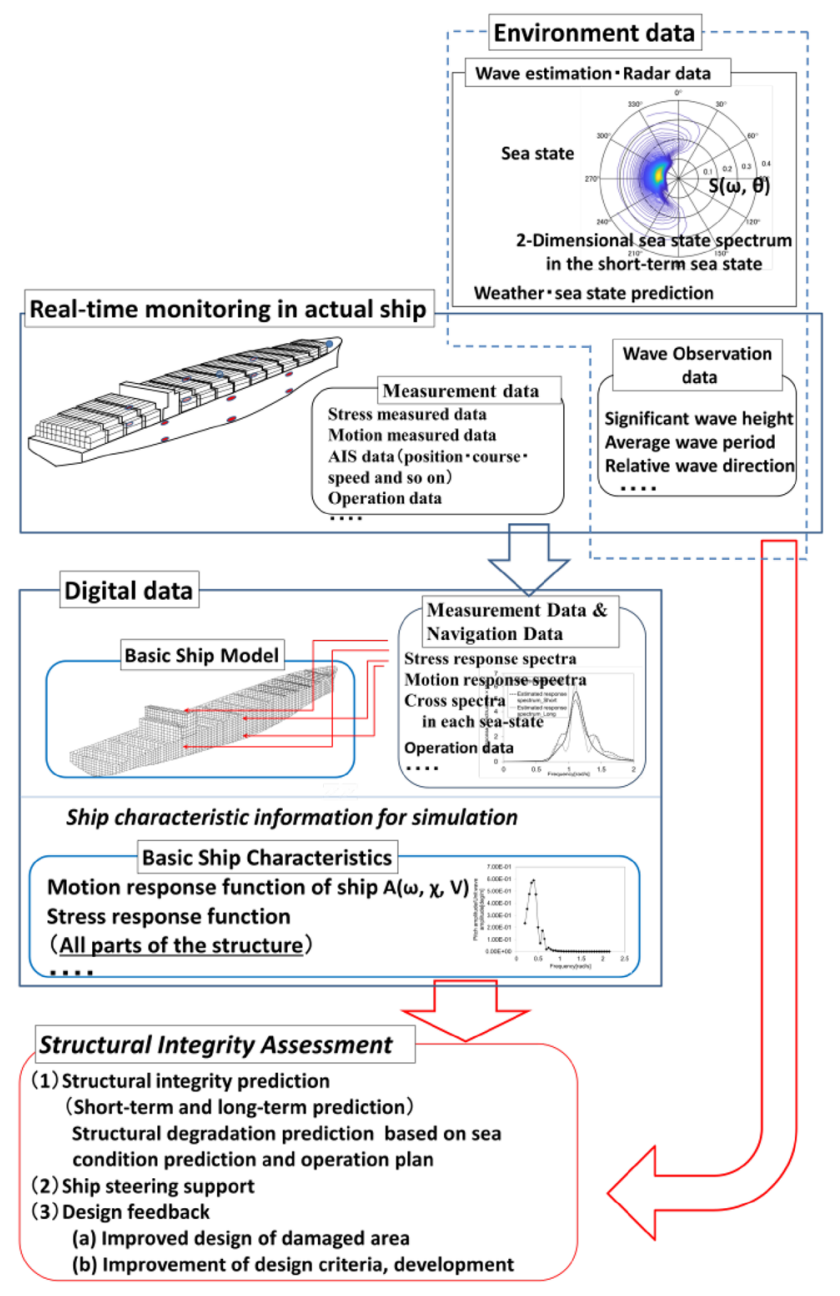

Fig. 1 The concept of digital twin

characteristics, such as low cost, ability to represent the actually encountering seas and to simultaneously process the measured data on board. As an existing important sea state estimation method using measured ship responses, nonlinear programming method has been developed in the past few decades, which can estimate the sea state by minimization of the difference between the response spectrum from the measured ship responses and defined response spectrum from the theory. Saito and Maeda [3-6] proposed sea state estimation method based on the ship motions (pitch, vertical acceleration) by using nonlinear programming, in which a standard ISSC wave spectrum is assumed, and the validity of the method is discussed. Tannuri et al. [7] reported works on wave spectrum estimation by using heave, pitch and sway response in which the wave spectrum is represented by the eight parameters, and it was verified that sway motion is insensitive to error of load variations. Furthermore, the statistical method using Bayesian model is proposed for estimation of directional wave spectra based on the ship motions (heave, pitch and roll) in Iseki et al. [8, 9] and it was verified the stable results can be obtained by using the method, but accuracy of the method will be lower for the small amplitude response of ship motions. Nielsen [10-12] summarized in a general review with regard to sea state estimation development. Then he compared two methods using wave spectra with parametric representation and arbitrarily shaped wave spectra based on Bayesian model through using the ship motions response, and the results indicated that it is difficult to propose one of the ship response-based methods in favour of the other, since they perform equally well. And the main technical methods of ocean wave evaluation are described in the review papers [13] and [14]. In recent years, Nielsen et al. have done the following work in ocean wave assessment. Nielsen et al. suggested a new method in 2015 which is to make the fitting of the measured response and the corresponding theoretically calculated one directly in the time domain $[15,16]$. Subsequently, Nielsen has proposed a practical approach which is a transformation from encounter to an absolute domain of wave spectral densities, and it is considered that this method is satisfactory through numerical simulation and experimental verification [17]. Brodtkorb et al. developed a simple method to solve the wave spectrum by using the iteration method. Under the condition of zero velocity and long-crested waves, the wave spectrum is estimated by the experimental ship, and a good result is obtained [18]. After that, considering the influence of ship speed and short-crested waves, Nielsen et al. extended the method and verified the effectiveness of the method [19]. In 2018, Nielsen developed a larger scale and more accurate wave estimation system using measurements data from several ships simultaneously [20]. In addition, the estimation method of a sea wave state was developed according to the motion of the semi-submersible platform [21, 22].

In this way, considerable efforts have been made to estimate the ocean wave spectra from the measured ship responses. In the literature, we can see that ship motions have been the most frequently used responses for sea state estimation. However, it is not explicitly studied which ship motions are best for wave state estimation. In addition, regarding large container ships with their length greater than $300 \mathrm{~m}$, the ship will not respond to relatively high-frequency waves, and therefore, it is concerned that the wave spectrum in the high-frequency zone cannot be estimated accurately. With the large-scale container ships in recent years, various aspects of research have been valued such as longitudinal strength taking account of hydroelasticity, grasp of wave condition, statistical properties of dynamic and static loads and so on. Therefore, a large-scale hull monitoring campaign was launched recently using 10 sister 14,000 TEU large container ships under the support of the Ministry of Land, Infrastructure, Transport and Tourism of Japan for $i$-Shipping operation [23]. In the project, hull girder bending stresses were measured as well as the bow vertical acceleration, ship 
motions and so on. The first ship was delivered in February 2016, and nine vessels have already been delivered as of November 2018. In 2017, Yoshihira et al. proposed a method to estimate ocean wave spectrum using measured hull girder vertical bending stress using these container ships [24]. In 2018, Chen et al. used two methods (the parameter method and the discretized wave spectra method) to discuss the wave state based on longitudinal bending stress and ship motion (pitch and roll) [25]. The results show that the higher accuracy is expected by using longitudinal bending stress than by using ship motion to estimate ocean wave, presumably due to the higher sensitivity of the longitudinal bending stress to the high-frequency waves than the ship motions.

In this study, the authors studied a new method to estimate arbitrarily shaped wave spectra using measured stress components and three cases are discussed. The first one is the combination of two components, vertical bending stress and horizontal bending stress. The second one is the combination of three components, vertical bending stress, horizontal bending stress and double bottom bending stress. The last one is the combination of three components of ship motion (pitch, roll and heave). The estimated sea states are compared with the ocean wave hindcast database and radar data, and then, accuracy and selection of appropriate combination of the responses are discussed.

\section{Wave spectrum estimation method}

\subsection{Image of wave spectrum estimation method}

In this section, first we give the concept of wave spectrum evaluation method in Fig. 2. The measured response spectrum in encounter frequency domain is obtained by Fast Fourier transform of the measured data (upper left in Fig. 2). On the other hand, the ship response spectrum is estimated by the response function, the assumed wave spectrum and the corresponding direction distribution. However, the obtained ship response spectrum is at the wave frequency domain. We need to transform the ship response spectrum from the wave frequency domain to the encounter wave frequency domain (upper right in Fig. 2). Then, we minimize the square of difference between measured response spectrum and the estimated response spectrum by using genetic algorithm method combined with modified Powell method (lower part in Fig. 2). Finally, the design variables that determine the wave spectrum are obtained.

Here, the image of the assumed wave spectrum with the design variable is shown in Fig. 3. The assumed wave spectrums is composed of 20 discrete points, that is to say, there are 20 design variables for representation of the shape of the spectrum. In addition, other design variables include the parameters $s$ representing concentration of directional

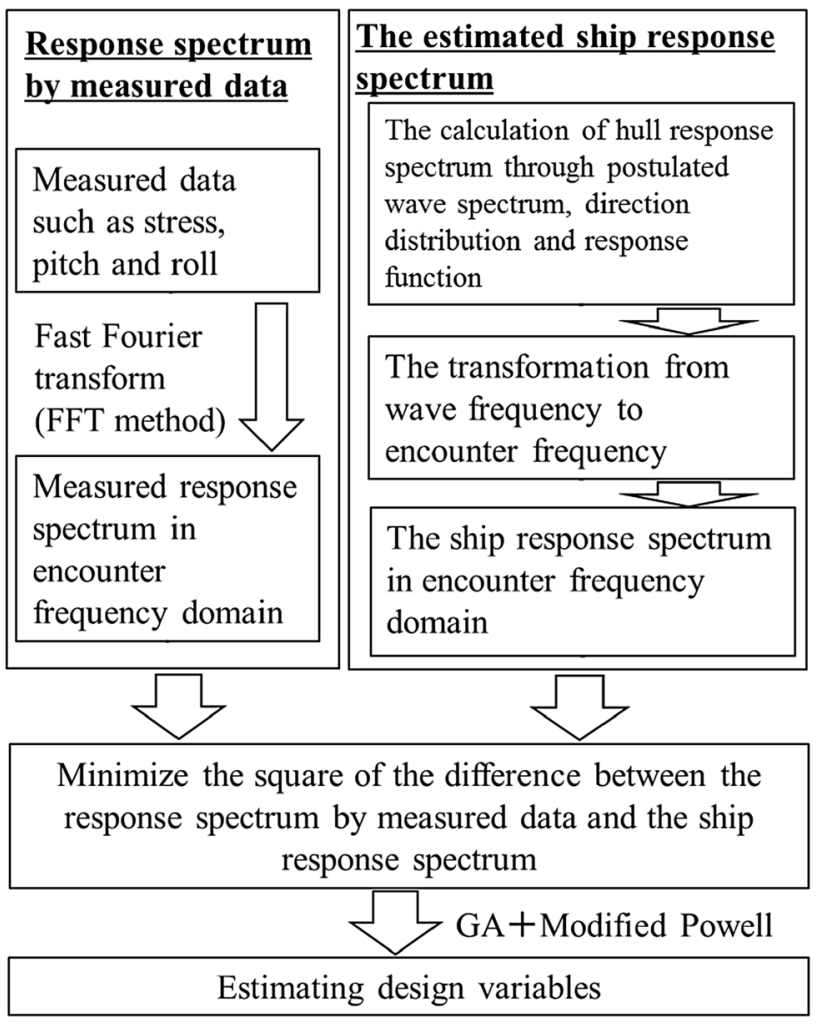

Fig. 2 Conceptual flowchart of wave spectrum estimation method

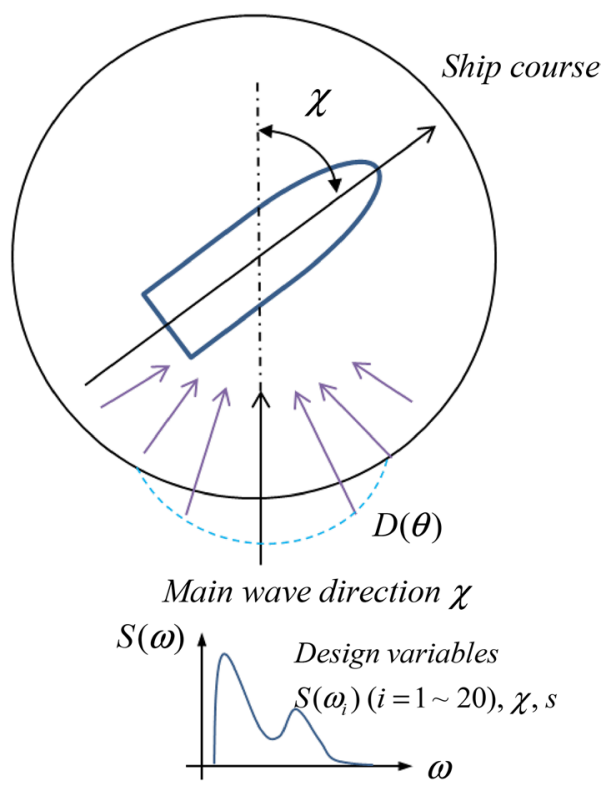

Fig. 3 Image of assumed wave spectrum

distribution of wave energy $D(\theta)$, and the relative angle $\chi$ between the ship course and the main wave direction. In the following chapters, we will elaborate on the formalization of the proposed method. 


\subsection{Frequency transformation}

In fact, because the measured data of ship are measured in the encounter frequency shifted from the actual wave frequency due to the Doppler effect, so we need to transform the wave frequency to the encounter frequency.

The relation between the encounter frequency and the wave frequency is as follows:

$\omega_{e}=\omega-\frac{V}{g} \omega^{2} \cos (\chi)$,

where $V$ is the ship speed $(\mathrm{m} / \mathrm{s})$ and $g$ is the gravity acceleration $\left(\mathrm{m} / \mathrm{s}^{2}\right), \omega_{e}$ is the frequency in the encounter frequency, $\omega$ is the frequency in the wave frequency.

From Eq. 1, the image of the relationship between $\omega_{e}$ and $\omega$ is shown in Fig. 4a about a transformation from the wave frequency domain to encounter frequency domain, taking the ship speed of 17.7 knot. When the typical wave period is assumed to be within the range of $0.5-1.0 \mathrm{rad} / \mathrm{s}$, typical

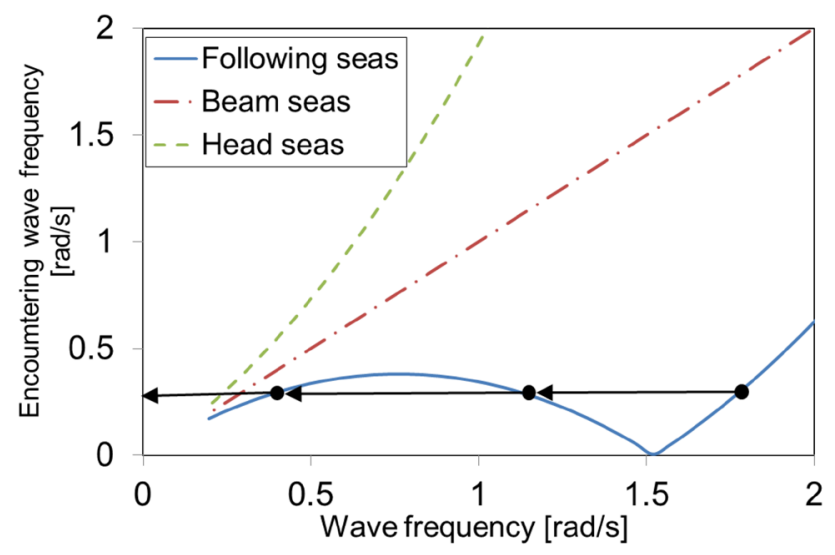

(a) Image of frequency transformation

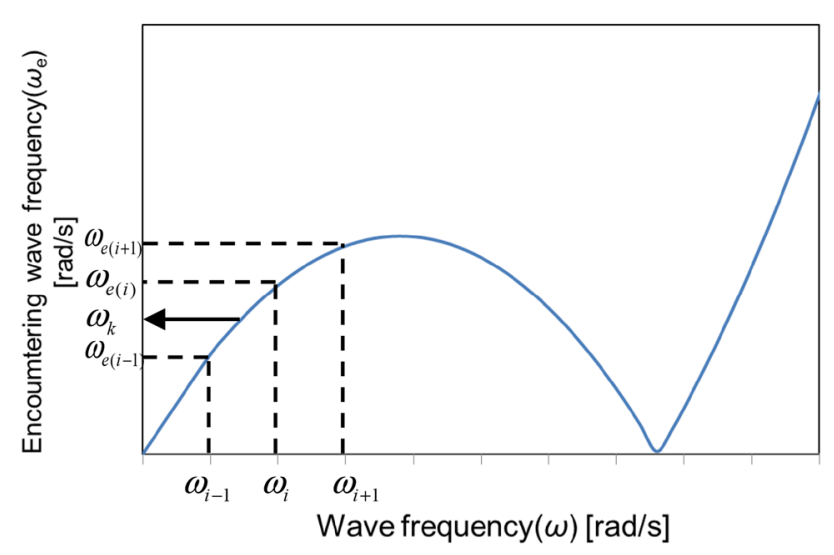

(b) Conversion of spectrum from $\omega$ to $\omega_{\mathrm{e}}$.

Fig. 4 Relation between absolute and encounter wave frequencies frequency band is around the peak of the curve for the following seas in Fig. 4a, while it moves to around the left slope of the curve when the ship speed becomes slower. We can find that one encounter frequency corresponds to one wave frequency in beam seas and head seas, however, one encounter frequency may correspond to three wave frequencies in following seas. Thus, the frequency transformation will be explained by taking the following seas as an example.

In fact, we assume that the space of frequency transformation before and after is unchanged when the frequency is transformed from wave frequency to encounter frequency. Thus, we consider a matrix $\mathbf{C}$ for converting from the wave frequency domain to the encounter frequency domain and its explanation is as follows.

First, we consider arbitrary three wave frequencies, represented by $\omega_{i-1}, \omega_{i}$ and $\omega_{i+1}$, respectively. Then, the three corresponding encounter frequencies can be calculated as follows applying Eq. 1 to each frequency.

$$
\begin{aligned}
\omega_{e(i-1)} & =\omega_{i-1}-\frac{V}{g} \omega_{i-1}^{2} \cos (\chi), \\
\omega_{e(i)} & =\omega_{i}-\frac{V}{g} \omega_{i}^{2} \cos (\chi), \quad i=2 \sim p-1, \\
\omega_{e(i+1)} & =\omega_{i+1}-\frac{V}{g} \omega_{i+1}^{2} \cos (\chi),
\end{aligned}
$$

where total number of discretization, $p=20$ in this study, and $i$ represents each discrete point.

Second, we consider an arbitrary frequency $\omega_{k}(k=1, \ldots$, $20)$, with the assumption that it falls in the area between $\omega_{e(i-1)}$ and $\omega_{e(i)}(i=1, \ldots, 20)$ as shown in Fig. 4. Therefore, we can use $\omega_{e(i-1)}$ and $\omega_{e(i)}$ to interpolate $\omega_{k}(k=1, \ldots, 20)$. And for the problem that the encounter frequency and the wave frequency are not one to one in the following seas, we consider the following operations, and add three wave frequencies to one encounter frequency.

$$
\begin{aligned}
& C_{k i}:=C_{k i}+\frac{\omega_{k}-\omega_{e(i-1)}}{\omega_{e(i)}-\omega_{e(i-1)}} \quad \begin{array}{r}
\text { when } \omega_{e(i-1)} \leq \omega_{k} \leq \omega_{e(i)}, \\
\text { or } \omega_{e(i)} \leq \omega_{k} \leq \omega_{e(i-1)},
\end{array} \\
& \text { but } \omega_{e(0)}=\left(2 \omega_{1}-\omega_{2}\right)-\frac{V}{g}\left(2 \omega_{1}-\omega_{2}\right)^{2} \cos (\chi),
\end{aligned}
$$

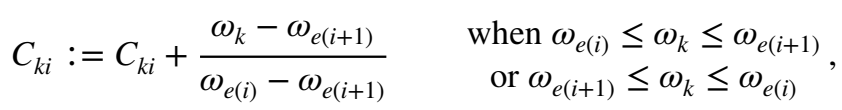
but $\omega_{e(n+1)}=\left(2 \omega_{n}-\omega_{n-1}\right)-\frac{V}{g}\left(2 \omega_{n}-\omega_{n-1}\right)^{2} \cos (\chi)$,

$k=1, \ldots, p \quad i=1, \ldots, p$,

where $C_{k i}$ is the $(k, i)$ component of the matrix $\mathbf{C}$. When Eqs. 3 and 4 are iterated throughout all the $k \mathrm{~s}$ and $i$, we can find that matrix $\mathbf{C}$ is obtained as an $p$ times $p$ matrix, 
representing the frequency transformation. Thus, we can realize the transformation of the ship response spectrum from wave frequency domain $R(\omega)$ to encounter frequency domain $R_{e}\left(\omega_{e}\right)$ through Eq. 5.

$\mathbf{R}_{e}\left(\omega_{e}\right)=\mathbf{C R}(\omega)$,

where, $\mathbf{R}_{e}\left(\omega_{e}\right)$ and $\mathbf{R}(\omega)$ are $p$-dimensional vectors. However, it is worth noting that the transformation from wave frequency to encounter frequency does not change the amount of energy of the response. Thus, the following equation is given for amending energy.

$R_{e}\left(\omega_{e}\right)=R(\omega) \frac{d \omega}{d \omega_{e}}$.

\subsection{Formulation}

In this study, the waves are considered as short-crested waves, and the ship response cross-spectra of components $m$ and $n$ can be related by the directional distribution function through the following integral:

$R_{m n}(\omega)=\int_{-\pi}^{\pi}\left[A_{m}(\omega, \chi+\theta)\right]\left[A_{n}(\omega, \chi+\theta)\right]^{*} \times S(\omega) \times D(\theta) d \theta$,

where the components $m(n)$ represent vertical bending stress, horizontal bending stress and double bottom bending stress response (or pitch, heave and roll response), respectively. $\omega$ denotes the angular frequency, $S(\omega)$ is the wave spectrum which is assumed as discretized wave model of 20 design variables in this study, $A_{m}(\omega, \chi+\theta)$ represents the ship motion response function of component $m . D(\theta)$ is the directional distribution function using Mitsuyasu-Goda type as following:

$D(\theta)=\frac{2^{2 s-1}}{\pi} \frac{\Gamma^{2}(s+1)}{\Gamma(2 s+1)} \cos ^{2 s}\left(\frac{\theta}{2}\right) \quad-\pi \leq \theta \leq \pi$,

where $\Gamma(z)$ is gamma function, $s$ denotes concentration of directional distribution of wave energy which is one of the design variables in this study.

In order to unify the order of component $m$, we need to normalize the response cross spectrum by using the root number $\left(R_{\text {mMax }}^{k e}\right)$ of the maximum value of response power spectrum of arbitrary component $m$ in encounter frequency domain which is obtained by FFT method for the measured data. Thus, Eq. 7 can be rewritten as follows:

$$
\begin{aligned}
R_{m n}(\omega)= & \int_{-\pi}^{\pi}\left[\frac{1}{R_{\text {mMax }}^{k e}} A_{m}(\omega, \chi+\theta)\right] \\
& \times\left[\frac{1}{R_{n \operatorname{Max}}^{k e}} A_{n}(\omega, \chi+\theta)\right]^{*} \times s(\omega) \times D(\theta) d \theta .
\end{aligned}
$$

Hence, applying the frequency conversion for the ship response spectrum in wave frequency domain, and discretizing Eq. 9, the matrix form to calculate the response spectrum in encounter frequency domain can be obtained as follows:

$\mathbf{R}_{m n}^{e}=\mathbf{C R}_{m n}=\mathbf{C A}_{n} \mathbf{A}_{m} \mathbf{S}$,

where $\mathbf{R}_{m n}^{e}$ is the ship response spectrum in encounter frequency domain, $\mathbf{R}_{m n}$ is the ship response spectrum in wave frequency, $\mathbf{A}_{n}$ is matrix of the response function of ship of component $n, \mathbf{S}$ is the wave spectrum, and $\mathbf{C}$ is frequency transformation matrix from wave frequency domain to encounter frequency domain.

We can assess the design variables $S\left(\omega_{i}\right), \chi, s$ through minimizing the object function as shown in Eq. 11, representing the square of the difference between the response spectrum by measured data and the estimated ship response spectrum:

$$
\begin{aligned}
F= & \int_{\omega_{1}}^{\omega_{n}} \sum_{m=1}^{3} \sum_{n=1}^{3}\left(R_{m n}^{e}\left(\omega_{e}\right)-\frac{R_{m n}^{k e}\left(\omega_{e}\right)}{R_{m M a x}^{k e} \times R_{n M a x}^{k e}}\right) \\
& \times\left(R_{m n}^{e}\left(\omega_{e}\right)-\frac{R_{m n}^{k e}\left(\omega_{e}\right)}{R_{m M a x}^{k e} \times R_{n M a x}^{k e}}\right)^{*} d \omega_{e} .
\end{aligned}
$$

In the discretized wave spectra, the two adjacent discrete wave frequencies may be added up into one encounter frequency. It can lead to a problem that the two magnitudes of the wave spectrum of the two wave frequencies can take any combination as long as they give proper magnitude in the one corresponding encounter frequency. Thus, the problem is underdetermined. To cope with this problem, a smoothing function is considered as follows:

$$
\begin{aligned}
\varepsilon & =\sum_{k=1}^{p-2}\left(S\left(\omega_{k}\right)-2 S\left(\omega_{k+1}\right)+S\left(\omega_{k+2}\right)\right)^{2} \cdot \Delta \omega \\
\Delta \omega & =\frac{1}{2}\left(\omega_{k+2}-\omega_{k}\right),
\end{aligned}
$$

where the $n$ is number for discretized wave spectra and is 20 in this study. Thus, the quadratic error is rewritten as follows:

$$
\begin{aligned}
F= & \int_{\omega_{1}}^{\omega_{n}} \sum_{m=1}^{3} \sum_{n=1}^{3}\left(R_{m n}^{e}\left(\omega_{e}\right)-\frac{R_{m n}^{k e}\left(\omega_{e}\right)}{R_{m M a x}^{k e} \times R_{n M a x}^{k e}}\right) \\
& \times\left(R_{m n}^{e}\left(\omega_{e}\right)-\frac{R_{m n}^{k e}\left(\omega_{e}\right)}{R_{m M a x}^{k e} \times R_{n M a x}^{k e}}\right)^{*} d \omega_{e}+\alpha \times \varepsilon,
\end{aligned}
$$

where $\alpha$ is the weight of the smoothing function. And the objective function minimization is achieved by the combination of the genetic algorithm for global search and the modified Powell method for subsequent local search. 


\section{The measured data and the response function of ship}

\subsection{Object ship and its data}

In this study, measured data are collected from two ships (called No. 1 and No. 2 hereinafter) among the 10 sister 14,000 TEU large container ships in the research project on hull structure health monitoring. The sensor arrangement related to this study is shown in Fig. 5. Double bottom stress sensors (LS4/LS3) and a wave radar were installed only onboard the ship No. 2, while the other sensors were installed on both the ships. (GMP + GMS)/2 represents the vertical longitudinal bending response of the ship, and (GMP - GMS)/2 represents the horizontal longitudinal bending response of the ship. The component to represent the double bottom bending response is obtained from the sensors LS3 and LS4, excluding the hull girder longitudinal bending component [26]. The heave response is obtained through double integral of ACC (acceleration) and position correction. The used data are shown in Table 1. Number of the hourly short-term response data was 120 for the ship No. 1 and 483 for the ship No. 2 , which excludes the data dubious about their stationary condition because of ship speed change greater than 2 knot or ship direction change greater than $15^{\circ}$ within the $1 \mathrm{~h}$. The data with the ship speed of less than $0.1 \mathrm{knot}$ were also excluded. The estimated sea state for each 1-h short term was compared with the wave hindcast data provided by Japan Weather Association (JWA). For the ship No. 2, comparison was made also with the wave spectrum obtained by the wave radar system.

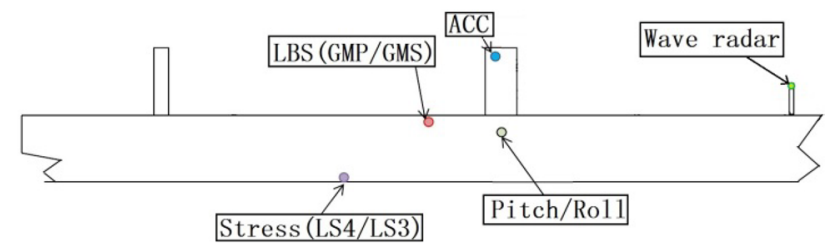

Fig. 5 Measuring point of ship (GMP at port, GMS at starboard, $L S 3$ at bottom centreline, LS4 at inner bottom centreline)

\subsection{Response function of ship}

In this study, the stress response functions are calculated by using ship motion analysis and entire ship FEM under a series of regular incident waves. Ship speed of $9.11 \mathrm{~m} / \mathrm{s}$ was given in the analysis of ship motion and wave loads. The calculated response functions of the longitudinal bending stress, horizontal bending stress and double bottom bending stress are shown in Fig. 6. The motion response functions are calculated using the linear strip method, and are shown in Fig. 7. The calculation was conducted under the ship speed of $9.11 \mathrm{~m} / \mathrm{s}$ for the subject 14,000 TEU container ship with the full loaded condition. We can estimate wave spectra using these response functions into Eq. 9.

By comparing the stress response function (Fig. 6) with the motion response function (Fig. 7), we can find that response of the motion shows a sharp reduction around the frequency higher than $0.6 \mathrm{rad} / \mathrm{s}$. However, the response of the stress is not reduced so sharply, and keeps a certain amount of magnitude even in the high-frequency area. This tendency is most prominent in the case of double-bottom bending stress as shown in Fig. 6c. Thus, it is considered that higher accuracy of estimated wave spectra may be expected by using the stress response functions, and the double bottom bending stress may further complement the other global stresses to improve the accuracy especially in the high-frequency zone.

\section{Estimated results}

\subsection{Estimated results using two stress components of longitudinal bending stress and horizontal bending stress for No. 1 ship}

In this section, we use the proposed method to estimate the wave states encountered by the ship No. 1 based on the two stress components of longitudinal bending stress and horizontal bending stress. $S\left(\omega_{i}\right)(i=1, \ldots, 20), s$ and $\chi$ are considered as design variables.

Table 1 The used data

\begin{tabular}{|c|c|c|c|c|}
\hline Ship number & Used data & Data quality & Measured data & Reference data \\
\hline No. 1 & 2016/9-2017/4 & 120 & Longitudinal bending stress and horizontal bending stress & Ocean wave hindcast database \\
\hline No. 2 & $2017 / 6-2017 / 7$ & 483 & $\begin{array}{l}\text { Longitudinal bending stress, horizontal bending stress and } \\
\text { double bottom bending stress } \\
\text { Pitch, roll and heave }\end{array}$ & $\begin{array}{l}\text { Ocean wave hindcast database } \\
\text { and radar data }\end{array}$ \\
\hline
\end{tabular}




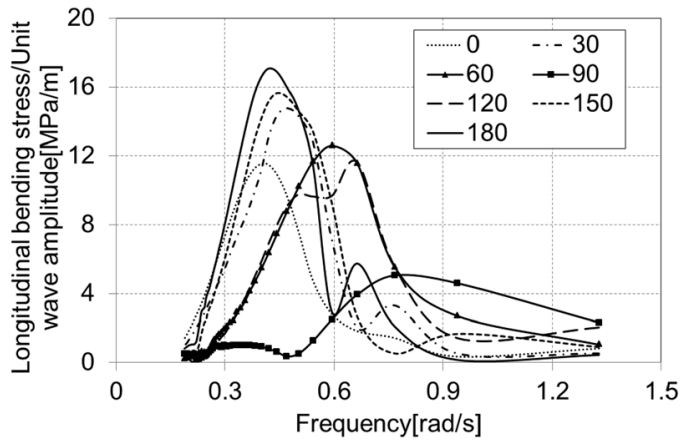

(a) Longitudinal bending stress

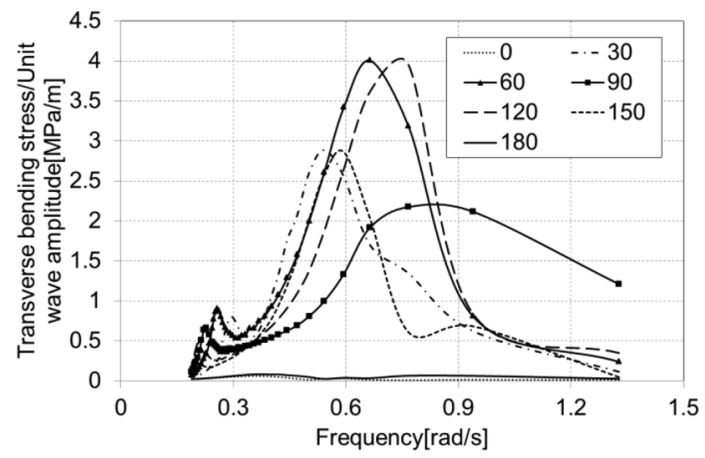

(b) Horizontal bending stress

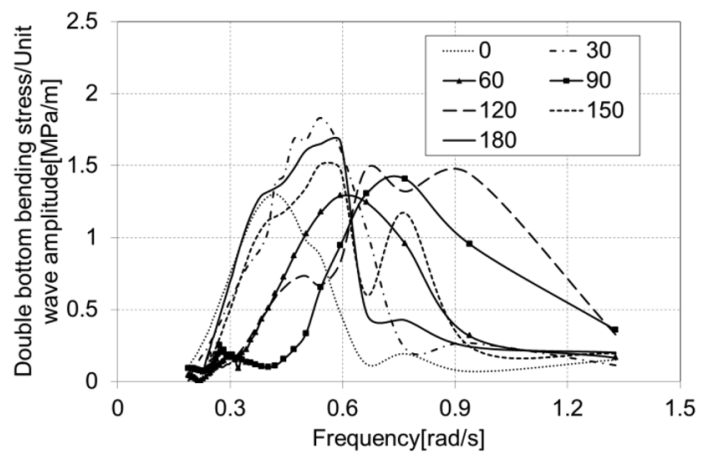

(c) Double bottom bending stress

Fig. 6 Response amplitude operator about stress for each wave direction

\subsubsection{The correlation between estimated sea states and reference sea states for 120 sea data}

In Fig. 8, we show the correlation between the estimated sea states and the reference sea states (wave hindcast) for 120 sea data with regard to the average wave period, the significant wave height and the relative wave direction. The correlation coefficients $r$ of average wave period and significant wave height are calculated by using Pearson correlation coefficient. Regarding the relative wave direction, the correlation coefficients $r$ are calculated by using circular correlation coefficient presented by Jammalamadaka and

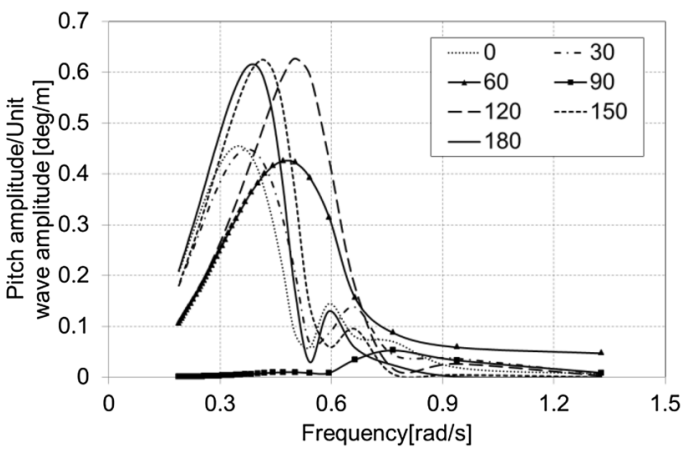

(a) Pitch motion

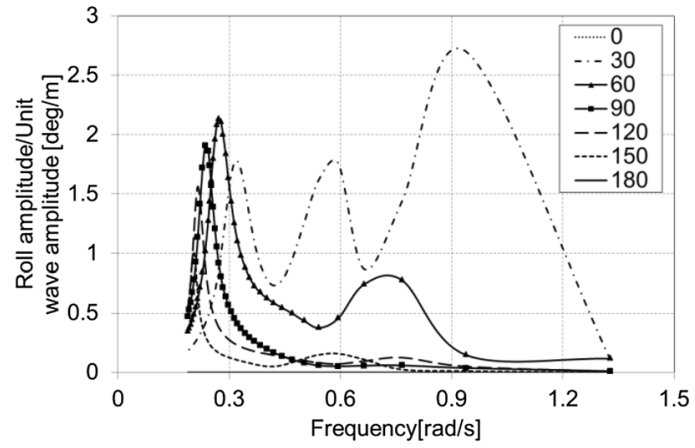

(b) Roll motion

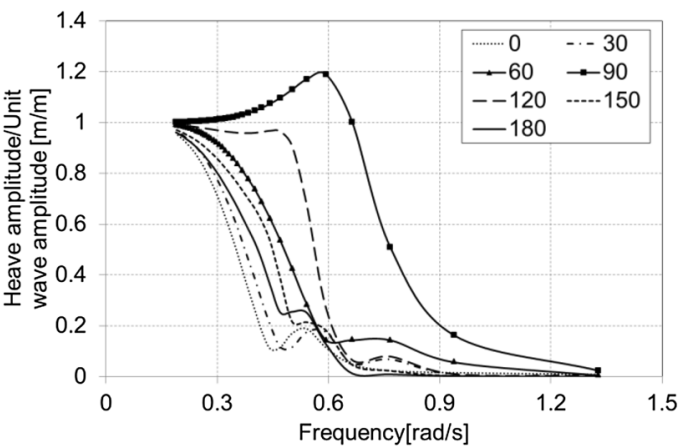

(c) Heave motion

Fig. 7 Response amplitude operator about motion for each wave direction

SenGupta [27]. The correlation coefficients are $0.056,0.322$ and -0.070 . No correlation was observed as to the average wave period and the relative wave direction, while we can observe a weak correlation in the significant wave height. In addition, the estimated significant wave height was in general smaller than that of the reference sea states.

Here, in order to investigate the effect of significant wave height on the accuracy of the estimation, we present the correlation figures of 89 sea data excluding calm seas with the significant wave height less than $2 \mathrm{~m}$ in Fig. 9. We can find that the dispersion of the average wave period and the relative wave direction decreases with the removal of the data with low significant wave height, and the 
correlation coefficients increases. Especially the correlation of relative wave direction becomes stronger. However, there still remain a small number of sea states, for which the estimation accuracy is insufficient.

\subsubsection{Two examples of hourly sea state}

In this section, the two sea states as shown in Table 2 are discussed for more detailed analysis. Case 1 was selected from the cases where quite good sea state estimation was

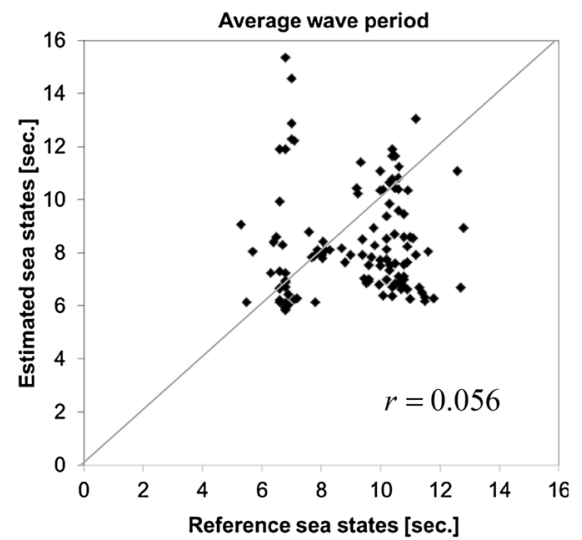

(a) Average wave period

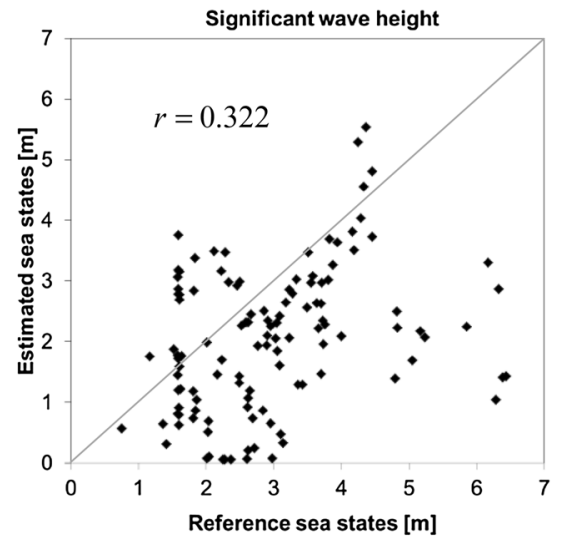

(b) Significant wave height

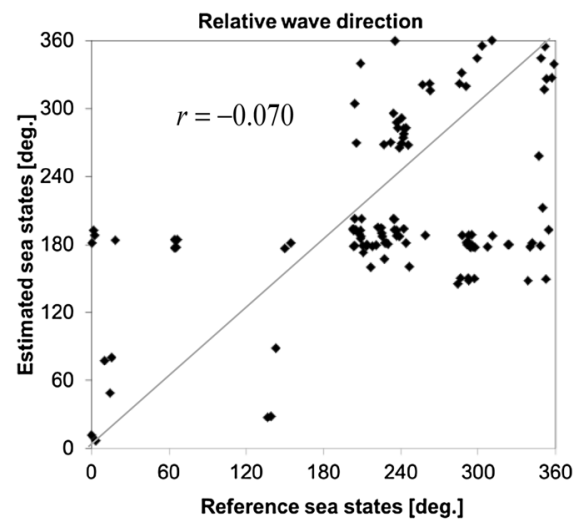

(c) Relative wave direction

Fig. 8 Correlation between estimated sea states and reference sea states including all the data

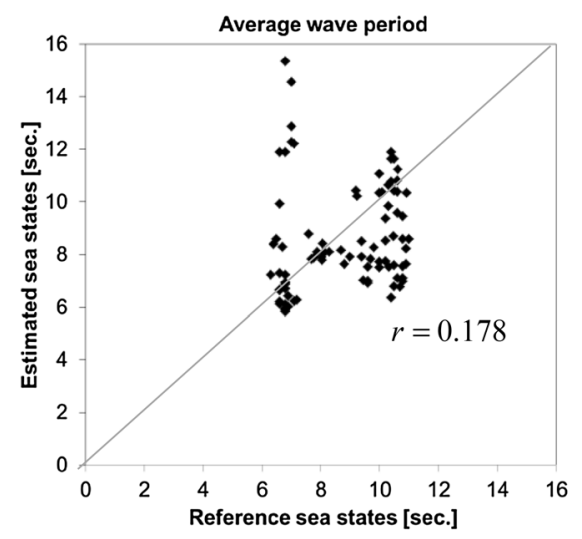

(a) Average wave period

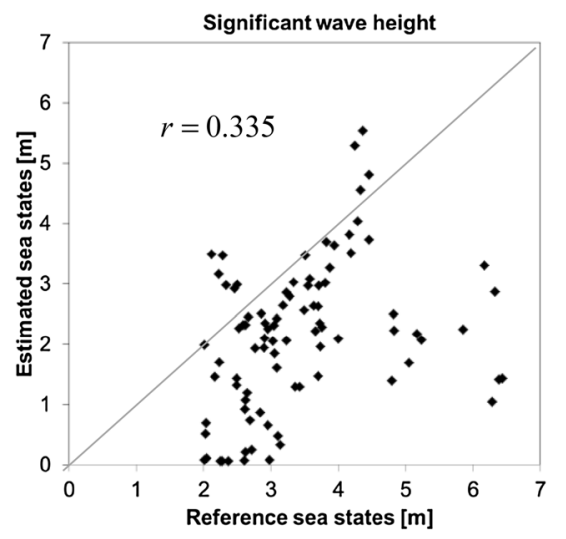

(b) Significant wave height

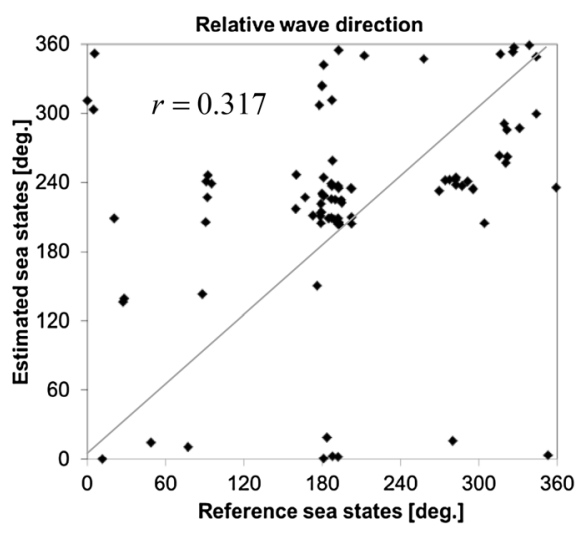

(c) Relative wave direction

Fig. 9 Correlation between estimated sea states and reference sea states excluding the significant wave height less than $2 \mathrm{~m}$

Table 2 Weather data

Time scale $\quad$ Average wave direction $\left({ }^{\circ}\right) \quad$ Significant wave height $(\mathrm{m})$

\begin{tabular}{llllr}
\hline Case 1 & $2017 / 01 / 1323: 00$ & 330.9 & 4.17 & 10.6 \\
Case 2 & $2016 / 09 / 2718: 00$ & 274.9 & 4.82 & 8.1 \\
\hline Case 1 & Ship speed (knot) & Course $\left(^{\circ}\right)$ & Relative wave direction & $\chi\left(^{\circ}\right)$ \\
Case 2 & 13.37 & 0.5 & Head seas & 209.6 \\
\hline
\end{tabular}


Table 3 Estimated results for case 1

\begin{tabular}{llll}
$\chi\left(^{\circ}\right)$ & $s$ & $\begin{array}{l}\text { Average } \\
\text { wave period } \\
(\mathrm{s})\end{array}$ & $\begin{array}{l}\text { Significant } \\
\text { wave height } \\
(\mathrm{m})\end{array}$ \\
\hline 209.6 & & 10.6 & 4.17 \\
202.44 & 50.0 & 10.37 & 3.81 \\
\hline
\end{tabular}
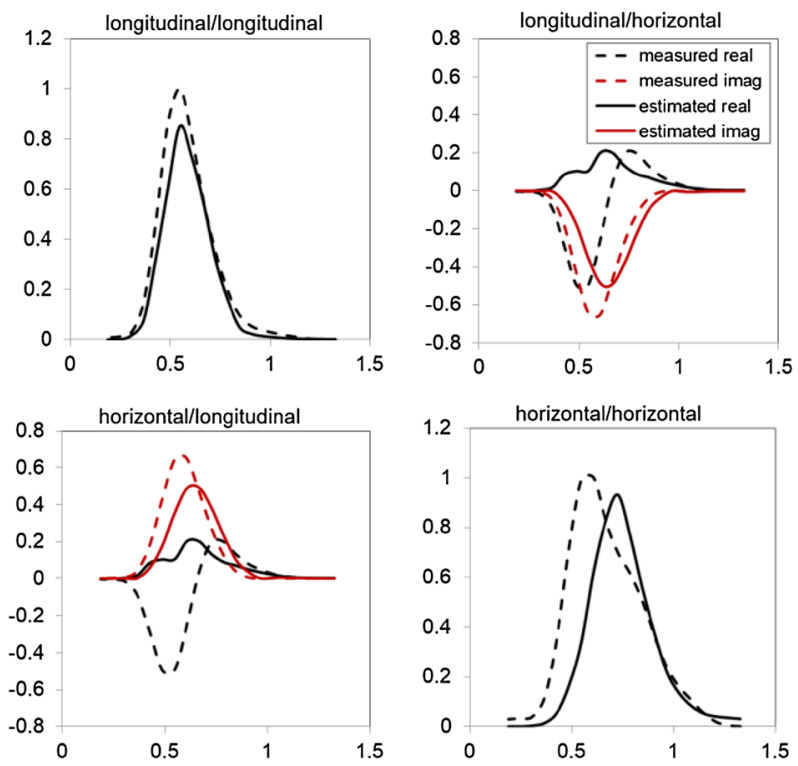

Fig. 10 Results of response spectrum estimation for case 1

given, while case 2 was selected from the cases with low estimation accuracy.

(1) Estimated results for case 1

The estimated results are given in Table 3 for case 1 . From the results, the average wave period, the significant wave height and relative wave direction are very close to the reference values. The results of the response spectra and the cross-response spectra are given in Fig. 10. In this figure, normalized response is used, divided by the maximum of bending stresses. We can see that the estimated response spectra agree with the measured response spectra.

In addition, the results of the wave spectrum and twodimensional wave spectrum are shown in Figs. 11 and 12, respectively. We can see that the estimated wave spectrum is closer to that from the ocean wave hindcast database.

(2) Estimated results for case 2

The estimated results are given in Table 4 for case 2 . From the results, average wave period and significant wave height are somewhat underestimated. We can also find that the relative wave direction is largely deviated from the weather data. The results of the response spectra and the cross-response spectra are given in Fig. 13. We can see that although the estimated response spectra agree quite well

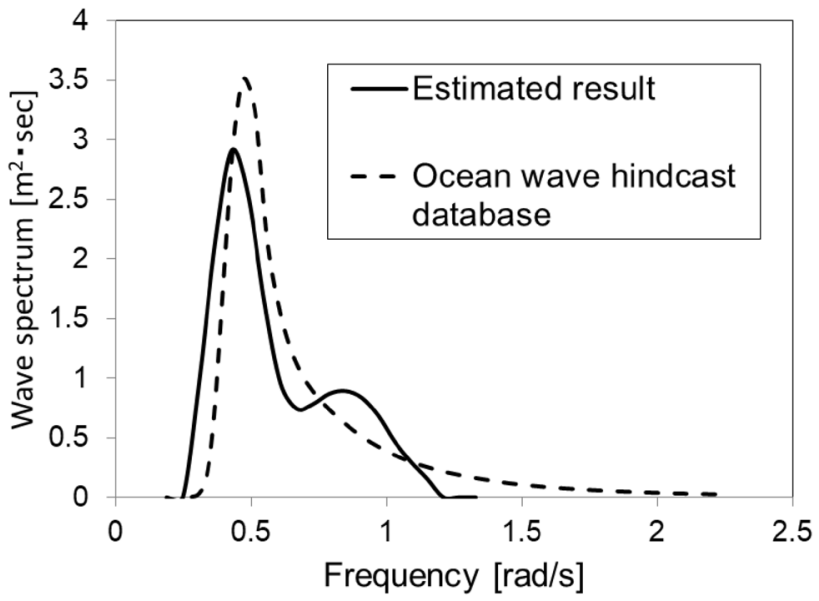

Fig. 11 Results of wave spectrum estimation

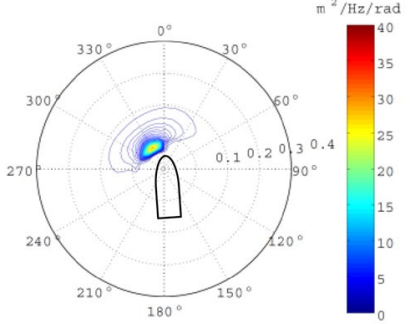

(a) The reference sea states

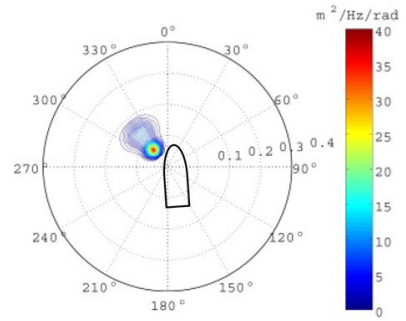

(b) The estimated result
Fig. 12 Two-dimensional wave spectrum (case 1)

Table 4 Estimated results for case 2

\begin{tabular}{|c|c|c|c|c|c|}
\hline & & $\chi\left(^{\circ}\right)$ & $s$ & $\begin{array}{l}\text { Average } \\
\text { wave period } \\
\text { (s) }\end{array}$ & $\begin{array}{l}\text { Significant } \\
\text { wave height } \\
\text { (m) }\end{array}$ \\
\hline \multirow[t]{2}{*}{ Case 2} & Weather data & 354.5 & & 8.10 & 4.82 \\
\hline & Estimated result & 192.6 & 22.7 & 7.78 & 2.49 \\
\hline
\end{tabular}

with the measured spectra, the estimated results for the relative wave direction and significant wave height are not good. Therefore, we try to investigate two-dimensional wave spectra of the reference sea states in Fig. 14a and the estimated result is given in Fig. 14b. We can observe two different major peaks in the reference wave spectrum in Fig. 14a. The proposed method can represent a wave spectrum with only one peak. Therefore, accurate estimation may not be expected in this kind of sea states with multiple spectral peaks.

In summary, from the results, we could observe that the significant wave heights are somewhat underestimated as a whole. In addition, because the sea states with poor 

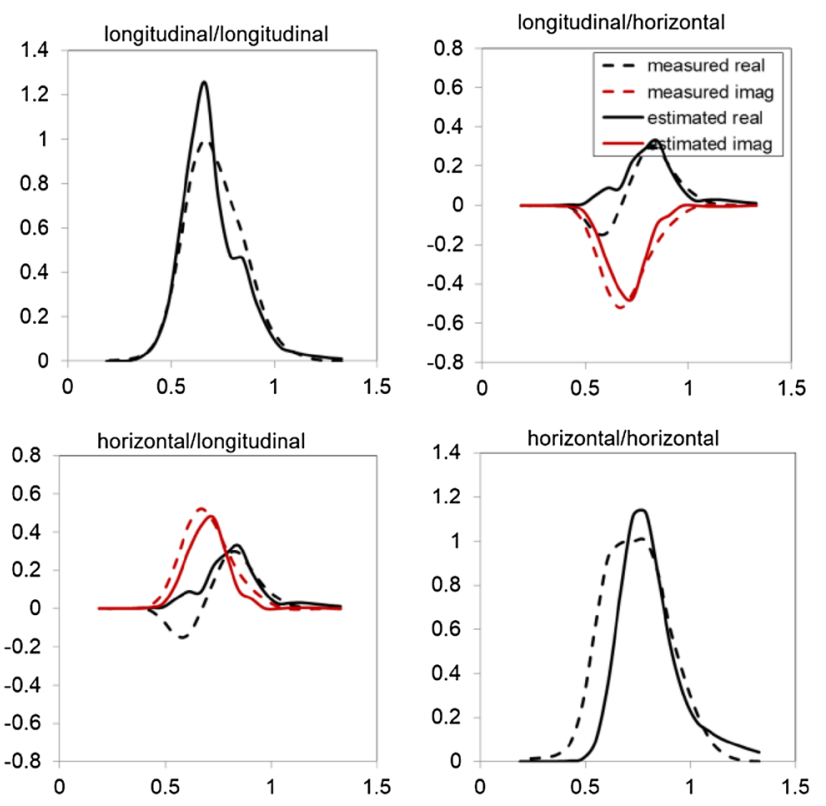

Fig. 13 Results of response spectrum estimation for case 2

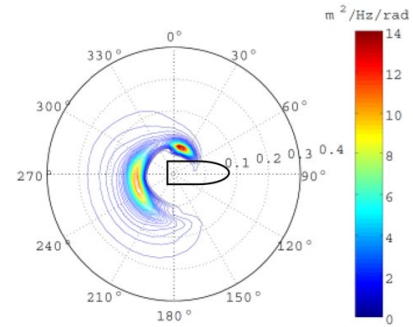

(a) The reference sea states

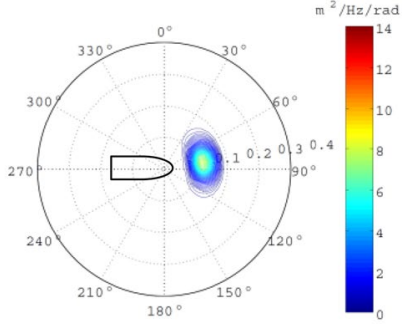

(b) The estimated result evaluation accuracy are almost multi-peak sea states, there is still a problem of poor precision for the proposed method that cannot express multi-peak sea states.

\subsection{Estimated results using three stress components of longitudinal bending stress, horizontal bending stress and double bottom bending stress for No. 2 ship}

In this section, we use the proposed method to estimate the wave states of No. 2 ship based on the three stress components of longitudinal bending stress, horizontal bending stress and double bottom bending stress. Here, the double bottom bending stress was selected expecting better estimation accuracy in high frequency waves thanks to the higher sensitivity of the double bottom bending to high frequency waves. $S(\omega), s$ and $\chi$ are considered as design variables.

\subsubsection{The correlation between estimated sea states and reference sea states for 483 sea data}

In Fig. 15, we show the correlation of the average wave period, the significant wave height and the relative wave direction for the 483 sea data. As shown in the vertical axis labels, the cross markers show the correlation between the estimated sea states (ordinate) and the radar data (abscissa), and the triangle markers show the correlation between the hindcast (ordinate) and radar data (abscissa). We can observe relatively good correlation between the hindcast data and the radar data. As to the correlation between the estimated sea states and the radar data, dispersion was serious and no correlation was observed in the average wave period, while a weak correlation can be seen in the relative wave direction and better agreement can be found in the significant wave height.

Here, in order to investigate the effect of significant wave height on the accuracy of the estimation, we present the

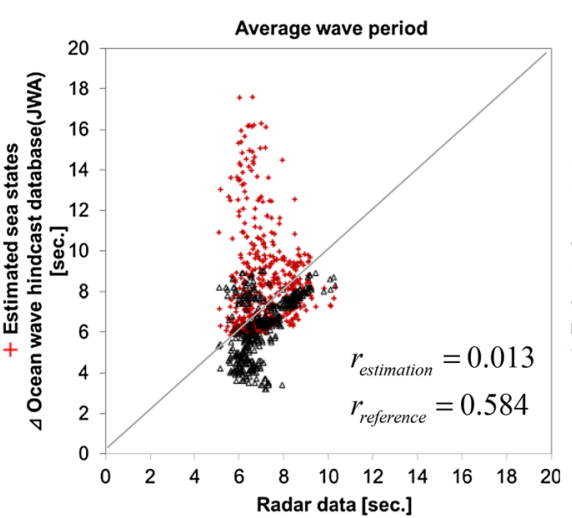

(a) Average wave period

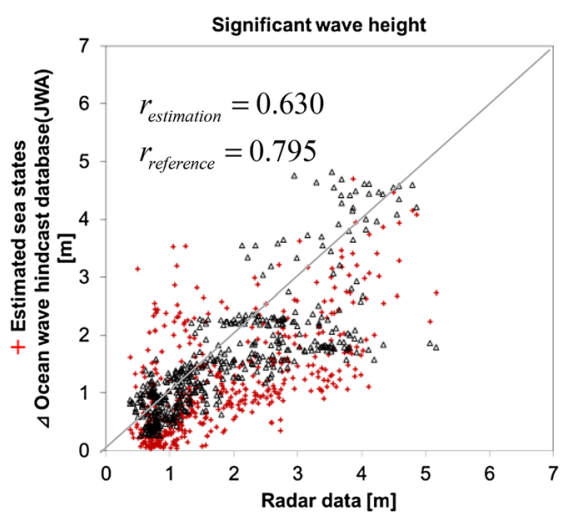

(b) Significant wave height

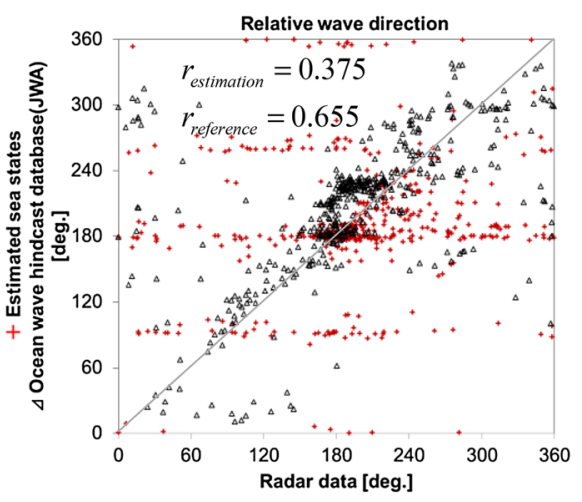

(c) Relative wave direction

Fig. 15 Correlation between estimated sea states and reference sea states including all the data 
correlation figures of sea data excluding calm seas with the significant wave height less than $2 \mathrm{~m}$ and $3 \mathrm{~m}$ in Figs. 16 and 17 , respectively. We can find that the dispersion of the average wave period and the relative wave direction decreases with the removal of the data with low significant wave height, and the correlation coefficients increases. However, the correlation of the significant wave height of the hindcast data and the radar data, and the estimated sea states and the radar data are both reduced. And there still remain a small number of sea states, for which the estimation accuracy is insufficient.

\subsubsection{Two examples of hourly sea state}

In this section, two sea states as shown in Table 5 are discussed for more detailed analysis.

(1) Estimated results for case 3

The estimated results are given in Table 6 for case 3 . From the results, the average wave period, the significant wave height and the relative wave direction are very close to radar data in this case. The results of the response spectra and the cross-response spectra are given in Fig. 18. We can see that the estimated response spectra agree with measurement data to some extent.

In addition, the results of the wave spectrum and twodimensional wave spectrum are shown in Figs. 19 and 20, respectively. We can see that the estimated wave spectrum is closer to that from the ocean wave hindcast database.

(2) Estimated results for case 4

The estimated results are given in Table 7 for case 4 . From the results, the average wave period is largely overestimated. We can also find that the relative wave direction is largely deviated from the weather data. The encounter wave frequency calculated from the average wave period and relative wave direction is:

- $0.41 \mathrm{rad} / \mathrm{s}$ according to the wave data from the radar,

- $0.34 \mathrm{rad} / \mathrm{s}$ according to the wave hindcast data,

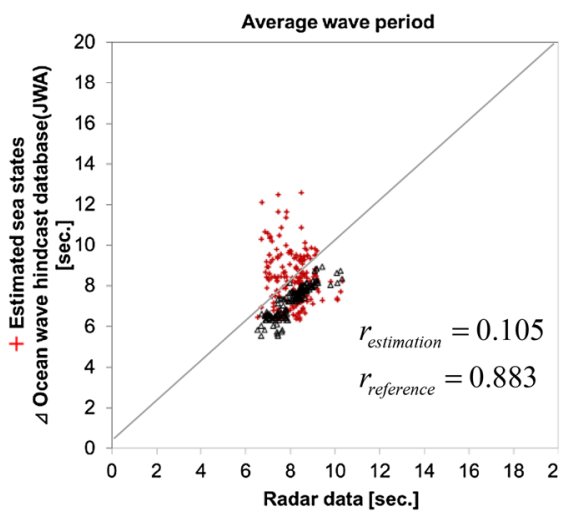

(a) Average wave period

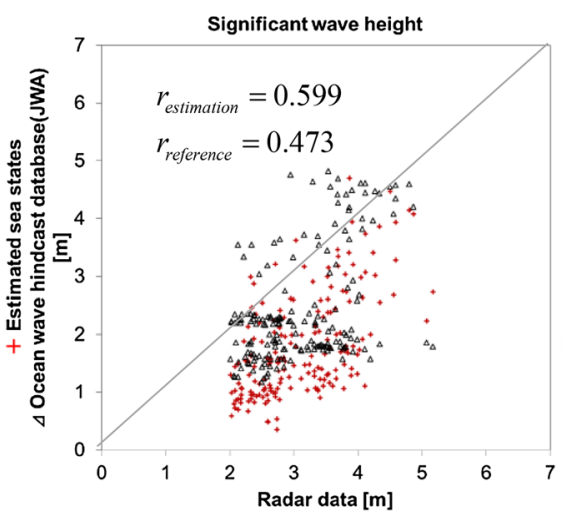

(b) Significant wave height

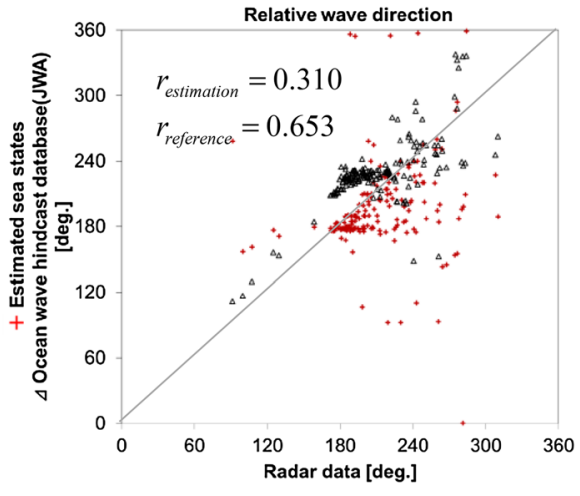

(c) Relative wave direction

Fig. 16 Correlation between estimated sea states and reference sea states excluding the significant wave height less than 2 (181 sea states)

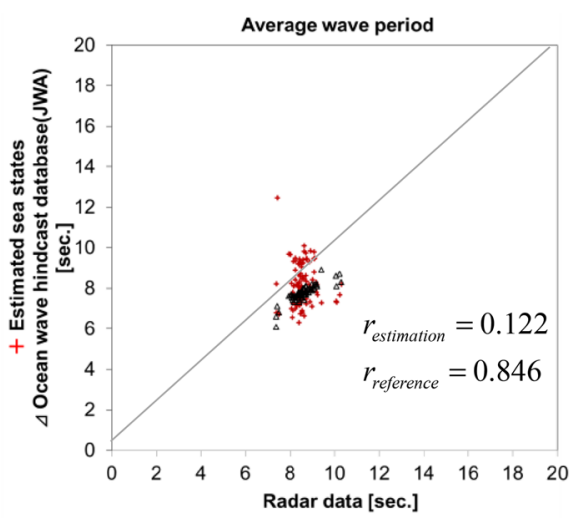

(a) Average wave period

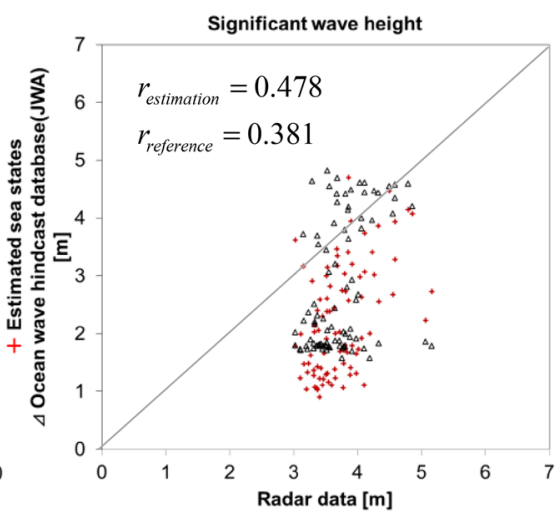

(b) Significant wave height

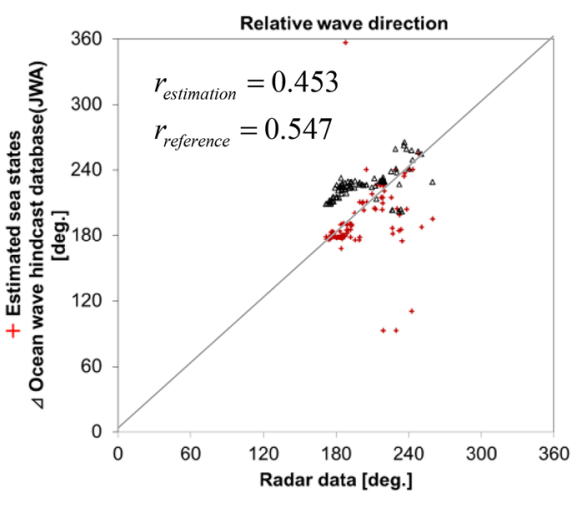

(c) Relative wave direction

Fig. 17 Correlation between estimated sea states and reference sea states excluding the significant wave height less than 3 (89 sea states) 
Table 5 Weather data base on radar data

Time scale $\quad$ Average wave direction $\left({ }^{\circ}\right) \quad$ Significant wave height $(\mathrm{m})$

Average

wave period

(s)

\begin{tabular}{lllll}
\hline Case 3 & $2017 / 07 / 18 ~ 15: 00$ & 248.0 & 3.91 & 9.09 \\
Case 4 & $2017 / 06 / 2622: 00$ & 151.7 & 1.20 & 6.14 \\
\hline & Ship speed (knot) & Course $\left(^{\circ}\right)$ & Relative wave direction & $\chi\left(^{\circ}\right)$ \\
\hline Case 3 & 14.79 & 285.5 & Head seas & 228.9 \\
Case 4 & 17.7 & 22.6 & Following seas & 40.2 \\
\hline
\end{tabular}

Table 6 Estimated results for case 3

\begin{tabular}{|c|c|c|c|c|c|}
\hline & & $\chi\left(^{\circ}\right)$ & $s$ & $\begin{array}{l}\text { Average wave } \\
\text { period (s) }\end{array}$ & $\begin{array}{l}\text { Significant } \\
\text { wave height } \\
\text { (m) }\end{array}$ \\
\hline \multirow[t]{3}{*}{ Case 3} & Weather data base on radar data & 217.5 & & 9.09 & 3.91 \\
\hline & $\begin{array}{l}\text { Weather data base on ocean wave } \\
\text { hindcast database }\end{array}$ & 228.9 & & 8.10 & 4.49 \\
\hline & Estimated result & 214.3 & 32.3 & 8.80 & 3.94 \\
\hline
\end{tabular}
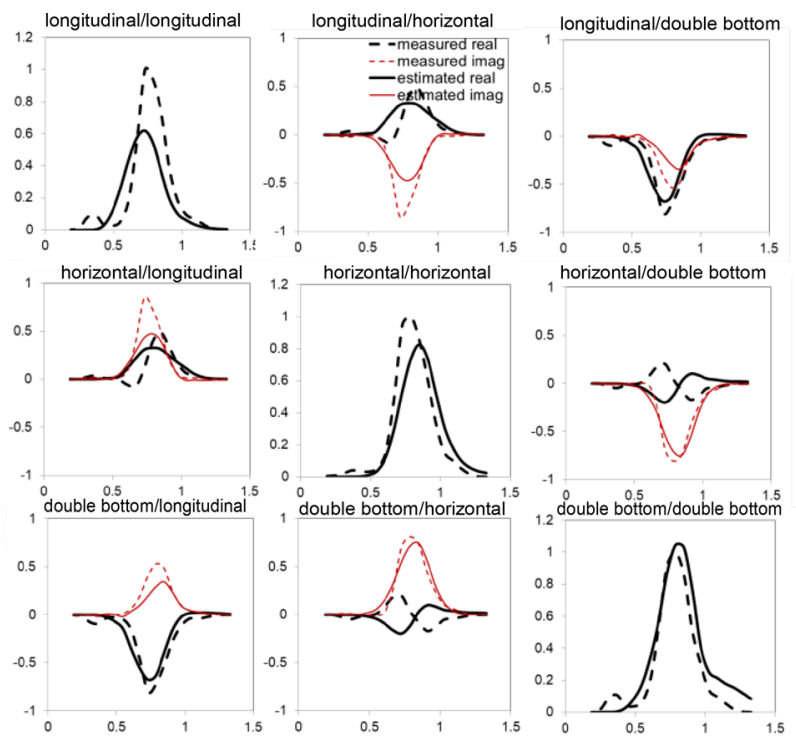

Fig. 18 Results of response spectrum estimation for case 3

- $0.45 \mathrm{rad} / \mathrm{s}$ according to the estimated wave data.

Although the wave estimation resulted in much larger wave period of $14.8 \mathrm{~s}$, it is observed to give similar encounter wave frequency as the reference data in combination with the estimated relative wave direction of $98.7^{\circ}$ (beam seas).

The results of the response spectra and the cross-response spectra are given in Fig. 21. We consider there is a possibility that the average wave period is overestimated because

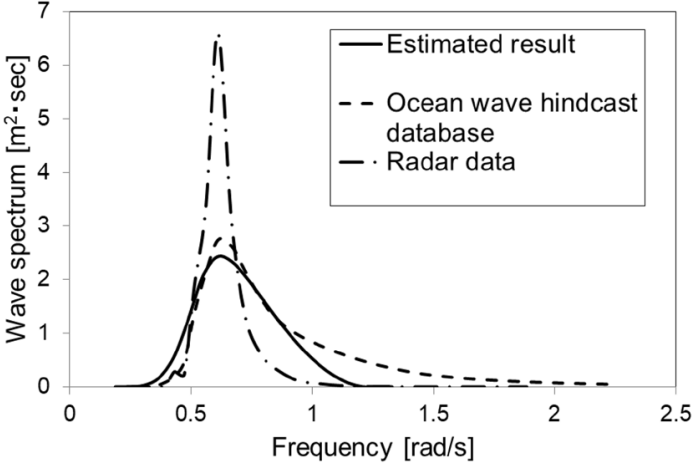

Fig. 19 Results of wave spectrum estimation and reference

it is observed that the estimated response spectra agree with the measured spectra to some extent in low-frequency domain. In addition, the two-dimensional wave spectrum of the weather data is shown in Fig. 22a, b, and the estimated results are given in Fig. 22c. From the two-dimensional wave spectrum of the radar data, we can see that the wave spectrum has many irregular small peaks. Reliability of the data looks dubious, but the waves are observed to come from various directions. The ocean wave hindcast database also shows the sea state of two peaks. Thus, similarly to the results in the previous section, we can state that it is difficult to estimate accurate sea state when the actual wave spectrum has multiple peaks. For the sea state of one peak, the proposed method seems to give accurate estimation of the sea states. Thus, the method to deal with multi-peak sea conditions is necessary to cover various actual encountering seas. 


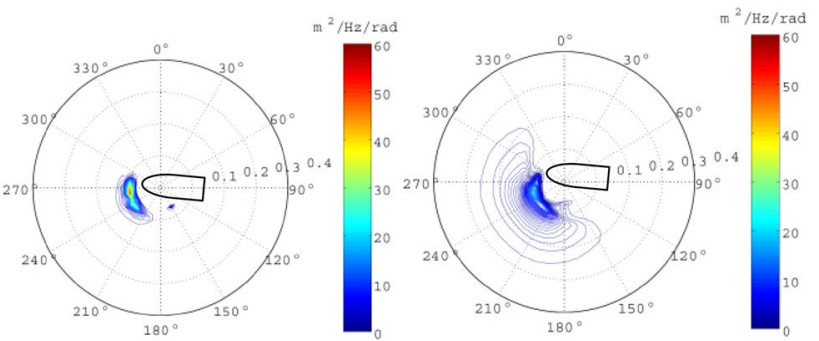

(a) The radar data (b) Ocean wave hindcast database

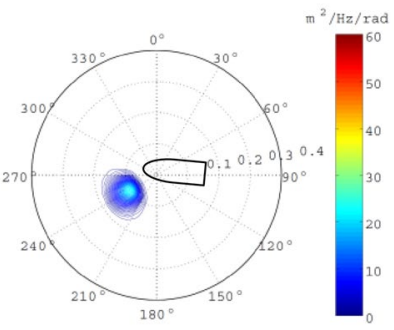

(c) The estimated result

Fig. 20 Two-dimensional wave spectrum (case 3)

\subsection{Estimated results using three motion components of pitch, roll and heave for No. 2 ship}

In this section, we use the proposed method to estimate the wave states of No. 2 ship based on the three motion components of pitch, roll and heave, $S(\omega), s$ and $\chi$ are considered as design variables.

\subsubsection{The correlation between estimated sea states and reference sea states for $\mathbf{4 8 3}$ sea data}

In Fig. 23, we show the correlation of the average wave period, the significant wave height and the relative wave direction for the 483 sea data. We can find that the dispersion of relative wave direction is quite serious, and the correlation coefficient between the estimated sea states and the radar data is very small. The significant wave height is as a whole overestimated.

Here, in order to investigate the effect of significant wave height on the accuracy of the estimation, we present

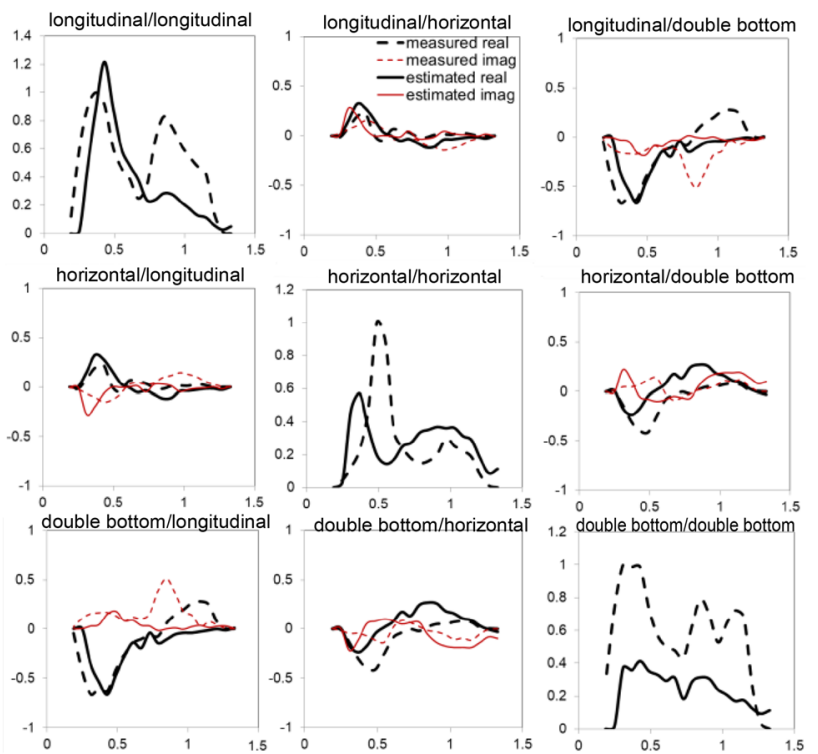

Fig. 21 Results of response spectrum estimation for case 4

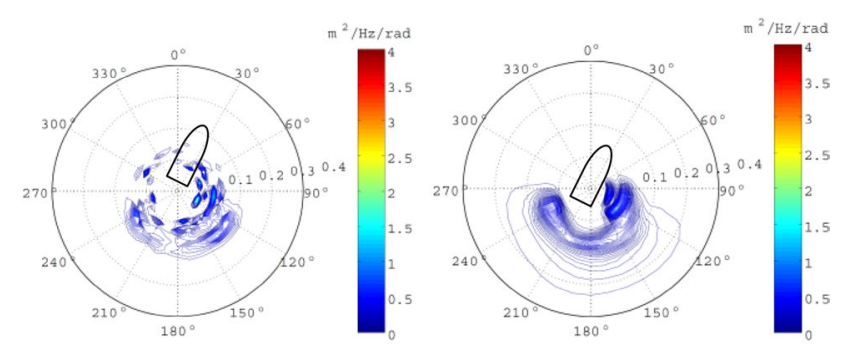

(a) The radar data

(b) Ocean wave hindcast database

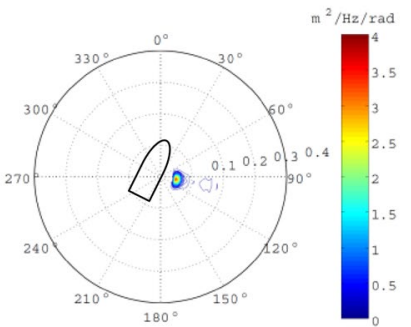

(c) The estimated result

Fig. 22 Two-dimensional wave spectrum (case 4)
Table 7 Estimated results for case 4

\begin{tabular}{|c|c|c|c|c|c|}
\hline & & $\chi\left({ }^{\circ}\right)$ & $s$ & $\begin{array}{l}\text { Average wave } \\
\text { period (s) }\end{array}$ & $\begin{array}{l}\text { Significant } \\
\text { wave height } \\
\text { (m) }\end{array}$ \\
\hline \multirow[t]{3}{*}{ Case 4} & Weather data base on radar data & 50.9 & & 6.14 & 1.20 \\
\hline & $\begin{array}{l}\text { Weather data base on ocean wave } \\
\text { hindcast database }\end{array}$ & 40.2 & & 7.50 & 1.21 \\
\hline & Estimated result & 98.7 & 43.58 & 14.8 & 0.79 \\
\hline
\end{tabular}




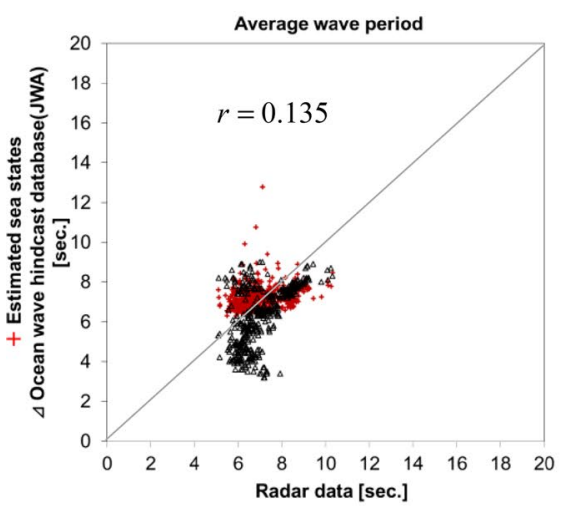

(a) Average wave period

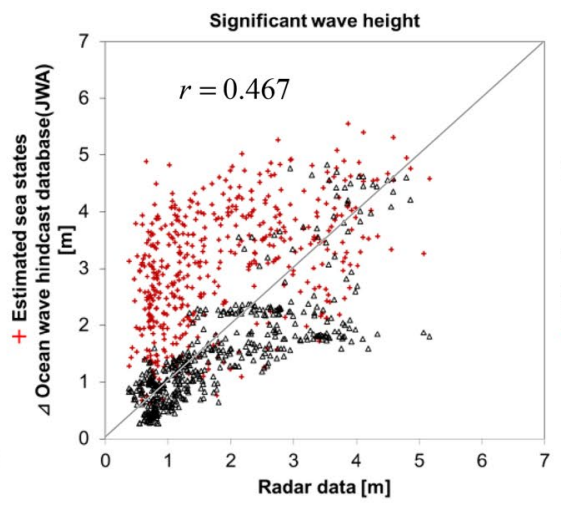

(b) Significant wave height

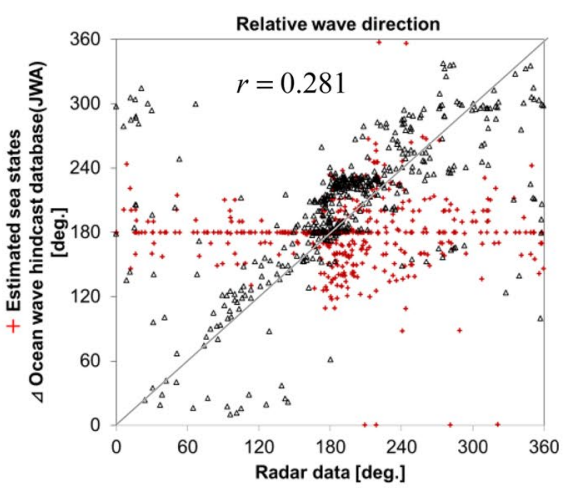

(c) Relative wave direction

Fig. 23 Correlation between estimated sea states and reference sea states including all the data

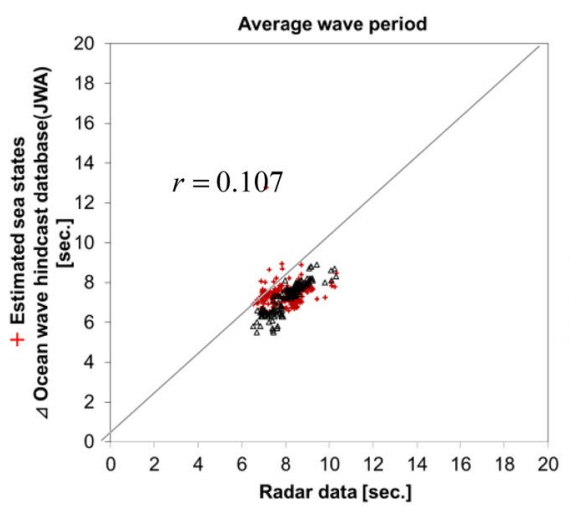

(a) Average wave period

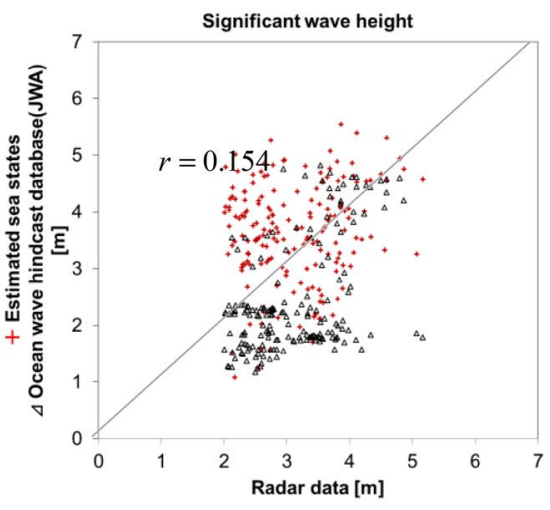

(b) Significant wave height

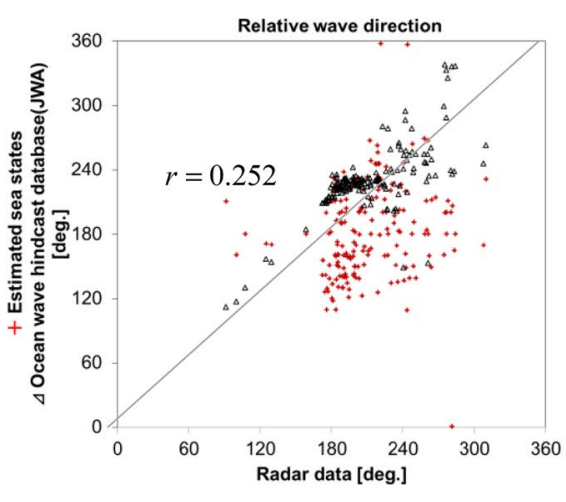

(c) Relative wave direction

Fig. 24 Correlation between estimated sea states and reference sea states excluding the significant wave height less than 2 (181 sea states)

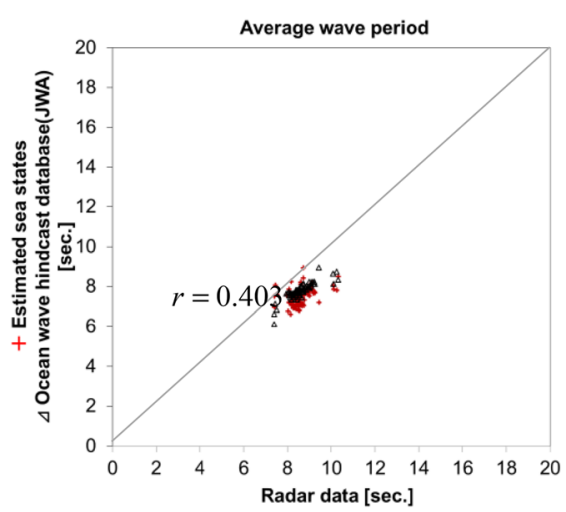

(a) Average wave period

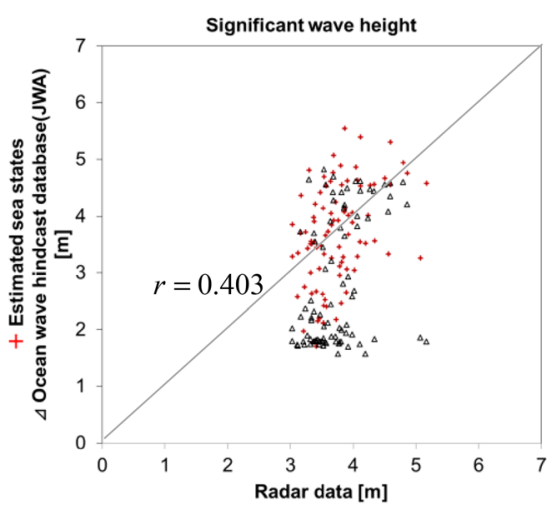

(b) Significant wave height

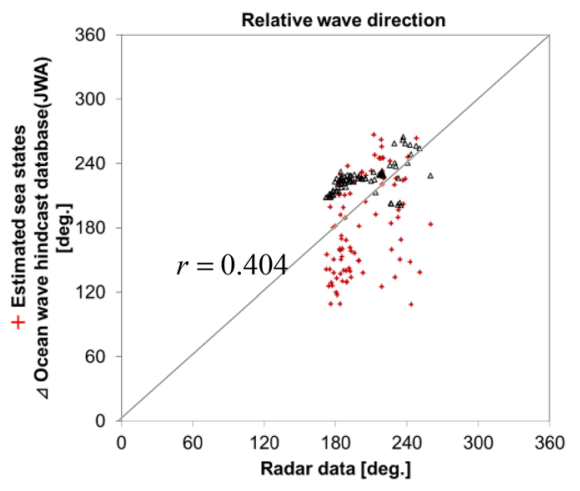

(c) Relative wave direction

Fig. 25 Correlation between estimated sea states and reference sea states excluding the significant wave height less than 3 ( 89 sea states) 
Table 8 Estimated results for case 4

\begin{tabular}{|c|c|c|c|c|c|}
\hline & & $\chi\left(^{\circ}\right)$ & $s$ & $\begin{array}{l}\text { Average wave } \\
\text { period (s) }\end{array}$ & $\begin{array}{l}\text { Significant } \\
\text { wave height } \\
\text { (m) }\end{array}$ \\
\hline \multirow[t]{3}{*}{ Case 4} & Weather data base on radar data & 50.9 & & 6.14 & 1.20 \\
\hline & $\begin{array}{l}\text { Weather data base on ocean wave } \\
\text { hindcast database }\end{array}$ & 40.2 & & 7.50 & 1.21 \\
\hline & Estimated result & 200.9 & 5 & 6.55 & 3.28 \\
\hline
\end{tabular}
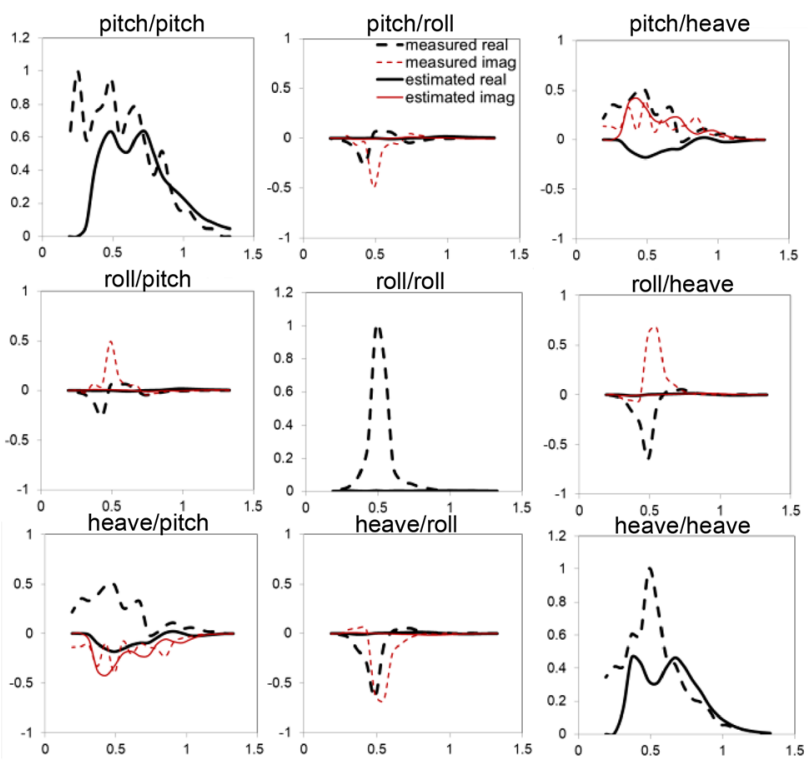

Fig. 26 Results of response spectrum estimation for case 4

the correlation figures of sea data excluding calm seas with the significant wave height less than $2 \mathrm{~m}$ and $3 \mathrm{~m}$ in Figs. 24 and 25, respectively. We can find that the dispersion of the average wave period and the relative wave direction decreases in case of the reference sea states excluding the significant wave height less than 3 , and the correlation coefficients increases. However, the correlation of the significant wave height of the estimated sea states and the radar data is reduced. And there still remain a small number of sea states, for which the estimation accuracy is insufficient.

We discuss case 4 in Sect. 4.2. The estimated results are given in Table 8 for case 4 by using motion responses. From the results, significant wave height is largely overestimated. And we can find the relative wave direction has largely deviated from the weather data. Similarly, the results of the response spectra and the cross-response spectra are given in Fig. 26. We can see that only estimated power response spectrums of pitch and heave agree with measurement data to some extent, while the other component has almost no good approximation. In addition, the results of the wave spectrum are shown in Fig. 27. From the results wave spectrum is overestimated relative to the reference value because

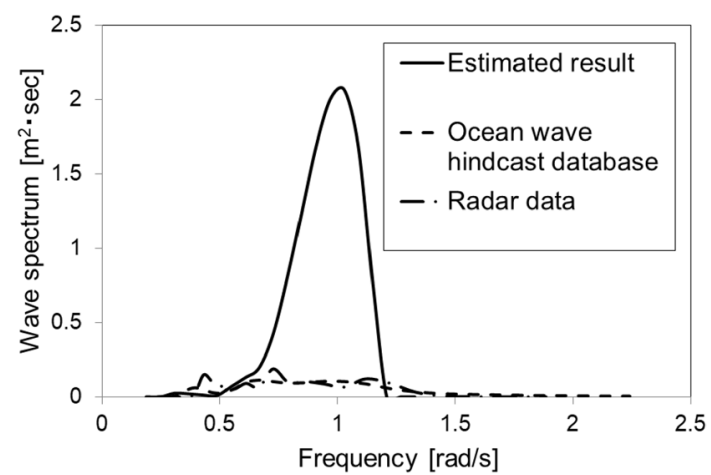

Fig. 27 Results of wave spectrum estimation and reference

the motion response has little response in the high-frequency domain.

Next, we compare the results based on stress responses and the results based on motion responses. We find that the correlation of the significant wave height and the relative wave direction based on stress responses is better than the motion response-based result by comparing Figs. 15, 16, 17b, c and Figs. 23, 24, 25b, c. In addition, we can also find that although the estimated result of the average wave period based on the motion response is closer to the reference value, the approximation results of the response spectrum are not good through observing of Fig. 26, especially for the power response spectrum and the cross-response spectrum of the roll motion. Then, we inspected also the other estimated results of motion response spectrum, and found the same problem in most sea states.

However, when we observe stress response spectrum (Fig. 21), we can see that almost every component of the stress response is appropriately approximated. That is to say, each response component plays a role in the estimation of sea state, but the result based on motion responses does not in such a way that the roll component of case 4 did not play any role in sea states estimation. Thus, as a whole, it is presumed that we can expect better sea state estimation based on stress responses than motion responses.

Additionally, for the No. 2 ship, there are fewer data available, especially for sea states with a wave significant height greater than $3 \mathrm{~m}$, and we can find that the sea states with wave significant heights greater than $3 \mathrm{~m}$ 
are almost all oblique head sea states. In the subsequent work, in order to evaluate the accuracy of the estimated results based on stress response, it is necessary to discuss the accuracy of the estimation under other relative wave directions such as beam seas, and following seas.

\section{Conclusions}

In this study, the authors proposed a method to estimate the ocean wave spectrum using measured stress components or motion components. A new approach is studied for the wave spectra estimation which is to estimate arbitrarily shaped wave spectra using nonlinear programming. We discussed the following three cases by using the proposed method:

1. Sea states are estimated through two stress components of longitudinal bending stress and horizontal bending stress for measured data of No. 1 ship.

2. Sea states are estimated through three stress components of longitudinal bending stress, horizontal bending stress and double bottom bending stress for measured data of No. 2 ship.

3. Sea states are estimated through three motion components of pitch, roll and heave for measured data of No. 2 ship.

From the observations of the results of estimation, we can conclude that:

1. The dispersion of the average wave period is serious when the stress responses are used to estimate sea states. However, the estimated results of the significant wave height and the relative wave direction are considered better.

2. The significant wave height is observed to be overestimated as a whole when the motion responses are used for the estimation. Evaluation results based on motion responses may be questioned because the estimated response spectrum does not agree with the measured one with regard to at least one component of the motions. On the other hand, estimation based on stress responses gives better results as a whole.

3. The main reason for the discrepancies between the estimation and the reference wave data may be attributed to the violation of the basic assumption of one peak spectra to estimate the wave spectra, while the actual directional wave spectra contain multiple peaks in many cases. Another possible reason is the difference in loading status (static condition) between numerical simulation and hull stress monitoring.
In order to achieve a more accurate evaluation of sea states, it is necessary to develop a more advanced method to effectively deal with multiple peaks in the wave spectrum. The authors are working on this issue using the same data as this paper, which will be reported in a separate issue.

In addition, for the No. 2 ship, there are fewer data available. Especially, the sea states with wave significant heights greater than $3 \mathrm{~m}$ are almost all oblique head sea states. In order to evaluate the accuracy of the estimated results based on stress response and the superiority of the double bottom bending stress response, further studies would be required including analysis of more number of hourly sea states measured in this project, and accurate evaluation of the estimated and reference sea states.

Lastly, we used real ship responses to estimate the real sea states, but confirmation of the validity of the present method in simpler waves is not sufficient. In the future work, we plan to apply the proposed method to estimate the waves generated in tank test, including regular waves, long-crested irregular waves and short-crested irregular waves, to confirm the validity on a step-by-step basis.

Acknowledgements This study was conducted as a part of the collaborative research project "Hull structure health monitoring of 14,000 TEU large container ships" under the support of the Ministry of Land, Infrastructure, Transportation and Tourism of Japan for i-Shipping operation. The authors would like to thank the project members from Japan Marine United Corporation, ClassNK, National Maritime Research Institute, Japan Weather Association, NYK Line, MTI Co., Ltd. and the University of Tokyo for their discussion and support.

Open Access This article is distributed under the terms of the Creative Commons Attribution 4.0 International License (http://creativeco mmons.org/licenses/by/4.0/), which permits unrestricted use, distribution, and reproduction in any medium, provided you give appropriate credit to the original author(s) and the source, provide a link to the Creative Commons license, and indicate if changes were made.

\section{References}

1. Okada, T. (1994) Integrated hull condition monitoring systemtechnical issues (hull design and construction), Integrated Hull Condition Monitoring System (IHCMS) Seminar, Sydney, Tokyo, London

2. Collette M, Zhan Z, Zhu L, Zanic V, Okada T, Arima T, Skjong R, Jeong HK, Egorov G (2018) Committee IV.1 Design principles and criteria, Proceedings of the 20th International Ship and Offshore Structures Congress (ISSC 2018): 549-607

3. Saito K, Maeda K (1997) An estimation of ocean wave characteristics based on measured ship motions. J Soc Nav Archit Jpn 182:231-237

4. Saito K, Maeda K (1998) 1998) An estimation of ocean wave characteristics based on measured ship motions (2nd report. J Soc Nav Archit Jpn 184:159-165

5. Saito K, Maeda K, Matsuda A, Suzuki S (2000) An estimation of ocean wave characteristics based on measured ship motions (3rd report). J Soc Nav Archit Jpn 2000(187):77-83 
6. Saito K, Maeda K, Akashi T (2001) An estimation of ocean wave characteristics based on measured ship motions (4th report). J Soc Nav Archit Jpn 2001(190):241-246

7. Tannuri E, Sparano J, Simos A, Da Cruz J (2003) Estimating directional wave spectrum based on stationary ship motion measurements. Appl Ocean Res 25(5):243-261

8. Iseki T, Ohtsu K, Fujino M (1992) Bayesian estimation of directional wave spectra based on ship motions. J Soc Nav Archit Jpn 172:17-25

9. Iseki T, Ohtsu K, Fujino M (1994) Bayesian estimation of directional wave spectra based on ship motions. J Soc Nav Archit Jpn 176:99-105

10. Nielsen U (2006) Estimation of on-site directional wave spectra from measured ship responses. Mar Struct 19(1):33-69

11. Nielsen UD, Stredulinksy DC (2012) Sea state estimation from an advancing ship — a comparative study using sea trial data. Appl Ocean Res 34:33-44

12. Nielsen UD, Andersen IMV, Koning J (2013) Comparisons of means for estimating sea states from an advancing large container ship. In: Proceedings of 12th PRADS, Changwon, South Korea

13. Nielsen UD (2016) A review of sea state estimation procedures based on measured vessel responses. Conf Proc Jpn Soc Nav Archit Ocean Eng 23:103-108

14. Nielsen UD (2017) A concise account of technologies available for shipboard sea state estimation. Ocean Eng 129:352-362

15. Nielsen UD, Bjerregård M, Galeazzi R, Fossen TI (2015) New concepts of shipboard sea state estimation. In: Proceedings of MTS/IEEE OCEANS15, Washington, DC, USA

16. Nielsen UD, Galeazzi R, Brodtkorb AH (2016) Evaluation of shipboard wave estimation techniques through model-scale experiments. In: Proceedings of MTS/IEEE OCEANS16, Shanghai, China

17. Nielsen UD (2017) Transformation of a wave energy spectrum from encounter to absolute domain when observing from an advancing ship. Appl Ocean Res 69:160-172

18. Brodtkorb AH, Nielsen UD, Sorensen AJ (2018) Sea state estimation using vessel response in dynamic positioning. Appl Ocean Res 70:76-86
19. Nielsen UD, Brodtkorb AH, Sorensen AJ (2018) A brute-force spectral approach for wave estimation using measured vessel motions. Mar Struct 60:101-121

20. Nielsen UD (2018) Sea state estimation using simultaneous data from multiple observation platforms. Conf Proc Jpn Soc Nav Archit Ocean Eng 27:37-40

21. Mas-Soler J, Simos AN, de Mello PC, Tannuri EA, Souza FL (2017) A preliminary assessment of the use of a large semi-submersible platform as a motion-based wave sensor, Proceedings of the ASME 2017 36th international conference on ocean, offshore and arctic engineering: Paper No. OMAE2017-61454

22. Mas-Soler J, Simos AN, Tannuri EA (2018) Estimating on-site wave spectra from the motions of a semi-submersible platform: an assessment based on model scale results. Ocean Eng 153:154-172

23. Okada T et al (2017) Outline of the research project on hull structure health monitoring of 14,000TEU large container ships. Conf Proc Jpn Soc Nav Archit Ocean Eng 24:31-35 (in Japanese)

24. Yoshihira Y, Okada T, Kawamura Y, Terada Y (2017) A study on the estimation method of an ocean wave spectrum using measured hull responses on 14,000TEU large container ships. Conf Proc Jpn Soc Nav Archit Ocean Eng 24:37-42 (in Japanese)

25. Chen X, Okada T, Kawamura Y (2018) Sea state estimation using measured hull responses on 14,000TEU large container ships. Proceedings of the 7th international maritime conference on design for safety, Kobe, Japan, pp 160-168

26. Chen J, Okada T, Kawamura Y, Chen X (2018) Full-scale measurement of whipping related double bottom responses on a 14,000 TEU container ship. Conf Proc Jpn Soc Nav Archit Ocean Eng 27:511-516

27. Jammalamadaka SR, SenGupta A (2001) Topics in circular statistics, vol 5. World Scientific Press, Singapore

Publisher's Note Springer Nature remains neutral with regard to jurisdictional claims in published maps and institutional affiliations. 